\title{
sciendo The analysis of shaft sinking progress as a function of technical and organizational parameters
}

doi:10.2478/mape-2019-0020

Date of submission to the Editor: 04/2018

Date of acceptance by the Editor: 07/2018

MAPE 2019, volume 2, issue 1, pp. 203-212

Łukasz Bołoz

ORCID ID: 0000-0002-7139-0558

AGH University of Science and Technology, Poland

\section{INTRODUCTION}

Shaft sinking can be carried out by traditional mining technique using drilling and blasting with explosive material or by mechanical cutting of the shaft face.

The traditional mining method consists in drilling blast holes in the face of the shaft, loading them with explosive material and blasting. However, this technique requires withdrawal of the staff for the time of blasting and then venting the shaft face. At large depths, this technique significantly limits the progress of drilling. In addition, serial implementation of all processes is required, i.e. drilling, blasting, loading and securing of side walls, which also has a negative impact on efficiency.

When choosing the method of mechanical cutting of the shaft face, the main factor is the physical properties of the excavated rocks as well as economic and organizational possibilities. The mechanical technique includes all methods of shaft sinking, which use mechanical cutting of rocks using hammers, full-scale drilling, or cutting with various types of tools. Mechanical methods can be carried out manually (hammering) or using a suitable machine (drilling, cutting). However, loading and transport of output can be carried out in series with shaft loaders or in parallel with continuous haulage (conveyors, pneumatic or hydraulic transport).

There are known solutions and machines from Sandvik, Wirth, Turmag and Herrenknecht, which were or are still used. These solutions are characterized by varying degrees of mechanization and automation of individual processes carried out during shaft sinking. However, the existing shaft sinking technologies have their weaknesses, mainly in the aspect of excavation in a compact rock mass. The progress achieved by them is unsatisfactory in comparison to the one assumed. The main obstacle to achieving the right progress is a series of activities resulting from the shaft lining technology (Krauze, 2018, Allenby \& Kilburn, 2015, Schmah, 2007, Casteel, 2009) and the failure rate, in particular of new solutions (Sitko et al., 2018). In connection with this, a new, unique solution for the mechanized shaft complex was developed (Krauze, 2018) or cabins of minings machines operators (Tokarczyk, 2015). Another possibility is the use of mechanical cutting using conical picks (Biały, 2016, Bołoz \& Krauze, 2018) or discs (Gospodarczyk et al., 2013, 2016, Kotwica, 2018). A measure of efficiency of the shaft complex is the daily progress of sinking. In the perspective of the entire investment, which is the completion of a complete

\footnotetext{
*boloz@agh.edu.pl
} 
shaft, the total sinking time is important. Therefore, analytical studies of the progress of sinking and sinking time for a shaft with a diameter of $9.5 \mathrm{~m}$ and a depth of $830 \mathrm{~m}$ for one of the Polish mines were carried out.

\section{MECHANIZED SHAFT COMPLEX OF THE NEW GENERATION}

For the purpose of shaft sinking in one of the Polish hard coal mines, a mechanized shaft complex of the new generation has been developed. This complex implements the following processes in parallel (Krauze, 2018):

- cutting - continuous process carried out by the cutting head attached to the working platform in a way that allows cutting the entire bottom of the shaft,

- loading and haulage - carried out continuously by a loader and a set of belt and bucket conveyors,

- temporary protection of side walls - realized by steel shields that simultaneously perform the function of expansion using built-in hydraulic cylinders.

Taking into account the mining and geological conditions and in agreement with the user, the assumptions have been specified: maximum shaft diameter of $9.5 \mathrm{~m}$; rock strength for uniaxial compression of $150 \mathrm{MPa}$; maximum capacity $40 \mathrm{~m}^{3} / \mathrm{h}$, bucket capacity $6 \mathrm{~m}^{3}$; the daily working time of a sinking machine for cutting, loading and transport is a maximum of 20 hours. The calculations have been carried out for a total shaft depth of $830 \mathrm{~m}$.

The subject complex is shown in Figure 1. The complex consists of a working platform 1 , a rotating ring 2 , a support system 3 , a stationary working platform 4 , a linear guide 5 , a sinking machine arm 6 , a cutting head 7 , an arm actuator 8 , a sliding system 9 , a short belt conveyor 10, a linear belt conveyor 11, a pouring place 12, a short bucket conveyor 13 , storage bin 14 , a long bucket conveyor 15 , a fixed platform 16 , an actuator lowering the work platform 17, ventube 18, an operator cabin 19, a short conveyor lifting system 20, a working platform rotation drive 21 .

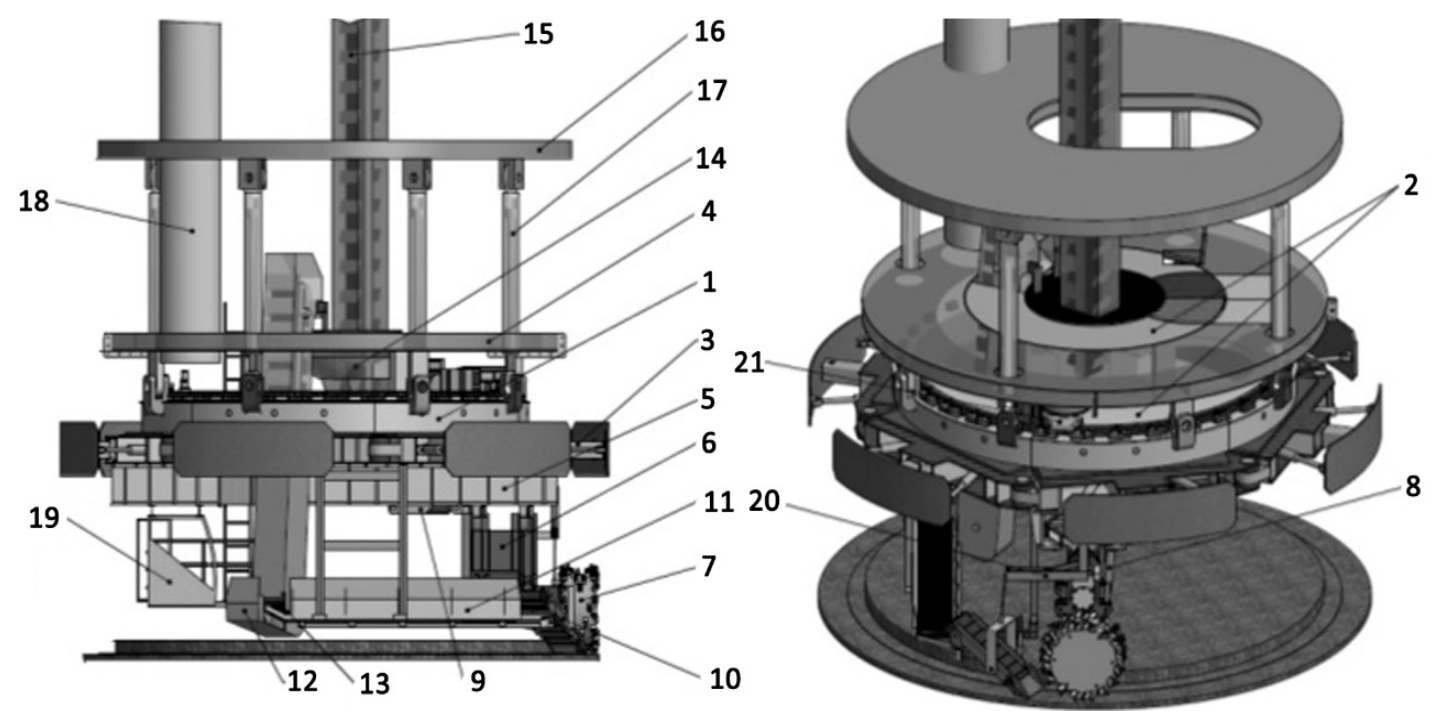

Fig. 1 The concept of a shaft complex of new generation

Source: (Krauze, 2018). 


\section{WORKING TECHNOLOGY OF THE SHAFT COMPLEX}

While developing the concept of the shaft complex, it was necessary to propose its working technology. The working technology must be implemented in a specific way due to the conditions at the place of shaft sinking and due to the machines used. Based on the principle of the complex work associated with the sinking technology, it was possible to analyse the progress. A number of complex concepts were developed, and performance evaluation was carried out for the final version (Krauze, 2017).

The shaft complex at the same time carries out the process of cutting, loading, output hauling off from the bottom of the shaft and temporary securing of the side walls. For the analysis, two cases of stroke of vertical actuators used to lower the sinking machine were taken (Figure 2).

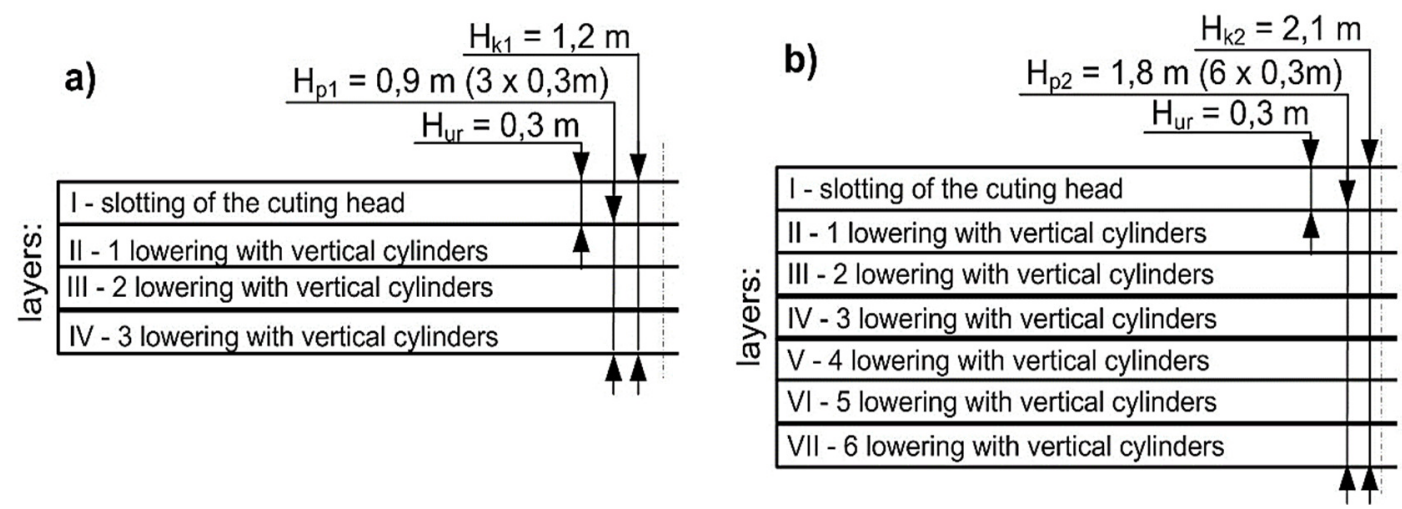

Fig. 2 The technology of making subsequent layers of the shaft a. side view for stroke $H_{p 1}=0.9 \mathrm{~m}$, b. side view for stroke $H_{p 2}=1.8 \mathrm{~m}$

According to one case, the sinking machine is lowered by means of actuators with a stroke of $0.9 \mathrm{~m}$, while in the second case the stroke is $1.8 \mathrm{~m}$. Moreover, for each case, it is possible to use a component with a web of $0.8 \mathrm{~m}$ or $1.0 \mathrm{~m}$, which together results in four cases. According to the adopted assumptions, cutting takes place using a horizontal axis cutting head. Before starting cutting, the working platform with the sinking machine is set at such a distance from the bottom of the shaft so that the cutting head can be slotted to a depth of $0.3 \mathrm{~m}$. The slotting is carried out by means of a pivoting arm of the cutting head. When lowering the working platform, the pouring place on its surface is getting distant from the long bucket conveyor, so it is necessary to lower the conveyor to the correct position. After setting and supporting the working platform, the slotting phase takes place. During slotting, the platform rotary ring performs a rotational movement with the working speed. The cutting head during the movement of the rotary ring of the platform cuts a slice of a toroidal shape with a cross-section similar to a rectangular one. The cutting head cuts a slice with a width equal to the web of the head $(0.8 \mathrm{~m}$ or $1.0 \mathrm{~m})$ and the height equal to the cutting depth of $0.3 \mathrm{~m}$ (maximum $0.35 \mathrm{~m}$ ). After cutting one slice, the head is raised, and then the return of the platform rotary ring to the starting position. Then it is necessary to slot the head into the new slice, i.e. in a new position, shifted towards the axis of the shaft by the value of the cutting head's web. Slotting into subsequent slices takes place after lowering the cutting head to the bottom of previously made cutting. During slotting into subsequent slices, the head moves along the linear guide towards the 
axis of the shaft simultaneously with the rotation of the ring, which results in the spiral movement of the head until reaching the position in the new slice (Figure 3).
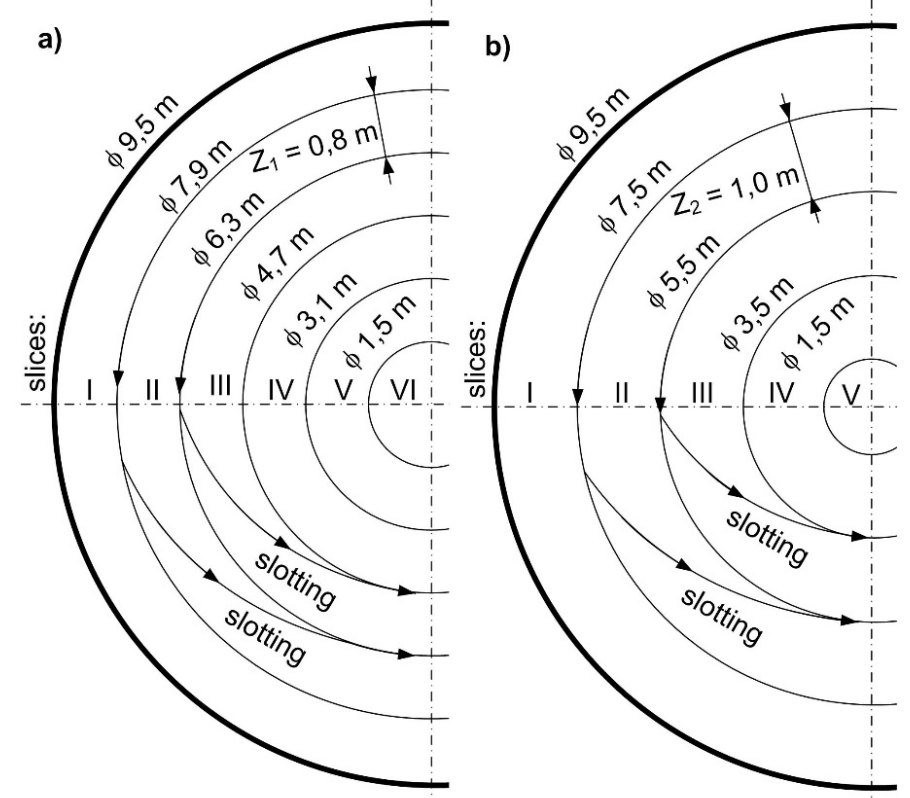

Fig. 3 Technology of making subsequent slices of the shaft a. top view for $Z_{1}=0.8 \mathrm{~m}$, b. side view for $Z_{2}=1.0 \mathrm{~m}$

Cutting of subsequent slices is carried out analogously until the full layer is made. During the phase of slotting and normal cutting the ploughshare loader moves behind the cutting head and loads the output onto the conveyor assembly. The long bucket conveyor transports the output outside the working platform to the required height resulting from the currently used equipment of the shaft complex. After making the full layer, the head returns to its initial position and another $0.3 \mathrm{~m}$ thick layer is made by lowering the platform with the sinking machine. For a version with platform actuators with a $0.9 \mathrm{~m}$ stroke, the machine will make a total of 4 layers. The first $0.3 \mathrm{~m}$ layer with the swinging arm and 3 changes of position with actuators of $0.3 \mathrm{~m}$. In the version with platform actuators with $1.8 \mathrm{~m}$ stroke, the machine will cut a total of 7 layers. The first $0.3 \mathrm{~m}$ layer with the swinging arm and 6 changes of position with actuators of 0.3 $\mathrm{m}$. After using the full stroke of the actuators, the actuators of the complex support are withdrawn and the complex lowered by $1.2 \mathrm{~m}$ (for $0.9 \mathrm{~m}$ actuators) or $2.1 \mathrm{~m}$ (for $1.8 \mathrm{~m}$ actuators). When lowering the complex or earlier, the platform and cutting head return to the original position. The original position means the vertical actuators pushed together, the arm swung out and the head positioned on the outer slice. When lifting the platform, it is necessary to raise simultaneously or earlier the long bucket elevator so that it follows along with the storage bin. The output from the long bucket conveyor is transported to buckets with a volume of $6 \mathrm{~m}^{3}$. On the working platform, the shaft lining can be mounted in parallel with the cutting process. The lining will be transported to the working platform and positioned with the use of appropriate devices. On the basis of geological surveys and uniaxial compression strength tests, the cutting head was designed and a possible linear cutting speed was determined. Then, the parameters of the sinking machine influencing the progress of cutting were calculated and summarized: 
- cutting head web (width): $Z_{1}=0.80 \mathrm{~m} ; Z_{2}=1.0 \mathrm{~m}$,

- layer thickness (depth of cutting): $\mathrm{H}_{\mathrm{ur}}=0.3 \mathrm{~m}$,

- rotational speed of the head: $n_{0}=60 \mathrm{rpm}$,

- maximum rotational speed of the platform (manoeuvring): $n_{p}=2.0 \mathrm{rpm}$,

- working rotational speed of the platform (during cutting): $n_{p c}=0.2 \mathrm{rpm}$,

- head structure and knife arrangement adapted to the type of rocks,

- type of picks: conical,

- stroke of vertical actuators: $\mathrm{H}_{\mathrm{p} 1}=0.9 \mathrm{~m}, \mathrm{H}_{\mathrm{p} 2}=1.8 \mathrm{~m}$,

- required drop in lowering the complex on ropes: $H_{k 1}=1.2 \mathrm{~m}, \mathrm{H}_{\mathrm{k} 1}=2.1 \mathrm{~m}$.

The sinking machine carries out further toroidal slices that make up the entire bottom layer of the shaft. At the given parameters, for the largest diameter of the shaft equal to $\phi 9.5 \mathrm{~m}$ and for the $0.8 \mathrm{~m}$ cutting head web it is necessary to make 6 slices (Figure $3 a$ ), while for the $1.0 \mathrm{~m}$ web only 5 slices are required (Figure $3 \mathrm{~b}$ ).

\section{ANALYSIS OF SHAFT SINKING EFFECTIVENESS}

On the basis of given geometrical and kinematic parameters, complex working technology and work organization, a multi-variant analysis of cutting progress was carried out. First, the cutting performance was determined during the implementation of one layer. The cutting is carried out at a constant rotational speed of the platform rotating ring of $0.2 \mathrm{rpm}$. In such a situation, the linear velocity of the cutting head (tangent to the radius of the shaft) varies in individual slices. Duration of each cut is 5 minutes. The Table 1 presents the values of linear velocity $v_{p s}$ and efficiency for subsequent slices $V_{u}$ as well as the volumes of subsequent slices $V_{s}$.

\section{Table 1}

Summary of linear velocity and cutting capacity for a constant rotational speed of the platform ring $n_{p c}=0.2 \mathrm{rpm}$

\begin{tabular}{|c|c|c|c|c|c|c|c|c|}
\hline & \multicolumn{4}{|c|}{ Web $Z=0.8 \mathrm{~m}$} & \multicolumn{4}{|c|}{ Web $Z=1.0 \mathrm{~m}$} \\
\hline & $\mathrm{D}_{\mathrm{s}}[\mathrm{m}]$ & $\begin{array}{c}\mathrm{v}_{\mathrm{ps}} \\
{[\mathrm{m} / \mathrm{min}]}\end{array}$ & $V_{s}\left[m^{3}\right]$ & $\begin{array}{c}V_{u} \\
{\left[m^{3} / h\right]}\end{array}$ & $\mathrm{D}_{\mathrm{s}}[\mathrm{m}]$ & $\begin{array}{c}\mathrm{v}_{\mathrm{ps}} \\
{[\mathrm{m} / \mathrm{min}]}\end{array}$ & $V_{s}\left[m^{3}\right]$ & $V_{u}\left[m^{3} / h\right]$ \\
\hline 1 & 9.5 & 6.0 & 10.7 & 128.6 & 9.5 & 6,0 & 13,1 & 157,0 \\
\hline 2 & 7.9 & 5.0 & 8.7 & 104.9 & 7.5 & 4,7 & 10,0 & 120,1 \\
\hline 3 & 6.3 & 4.0 & 6.8 & 81.3 & 5.5 & 3,5 & 6,9 & 83,1 \\
\hline 4 & 4.7 & 3.0 & 4.8 & 57.6 & 3.5 & 2,2 & 3,8 & 46,2 \\
\hline 5 & 3.1 & 1.9 & 2.8 & 34.0 & 1.5 & 0,9 & 0,9 & 10,4 \\
\hline 6 & 1.5 & 0.9 & 0.9 & 10.3 & & & & \\
\hline
\end{tabular}

The value of the output loosening coefficient $\mathrm{k}_{\mathrm{r}}=1.4$ was assumed. The given $D_{s}$ diameters are the outer diameters of the slice. The calculations were carried out for the head of $0.8 \mathrm{~m}$ and $1.0 \mathrm{~m}$ web.

After each full rotation, the rotary ring must return to the original position (one turn back), that is, for the entire layer it must make 6 rotations for the $0.8 \mathrm{~m}$ web and 5 for the $1.0 \mathrm{~m}$ web in the opposite direction to cutting. With a maneuvering rotational speed of the ring $n_{p}=2 \mathrm{rpm}$ it will take a total of 3 minutes for the $0.8 \mathrm{~m}$ web and 2.5 minutes for $1.0 \mathrm{~m}$ web. Assuming the theoretically given values for analysis, one can determine the yield and volume of the output when cutting one layer. Taking into account the above values, the average cutting efficiency for one layer was obtained: 
$\mathrm{V}_{\mathrm{u} 1}=63.1 \mathrm{~m}^{3} / \mathrm{h}$ for the $0.8 \mathrm{~m}$ web and $\mathrm{V}_{\mathrm{u} 2}=75.8 \mathrm{~m}^{3} / \mathrm{h}$ for the $1.0 \mathrm{~m}$ web. Execution of one layer taking into account the time of ring return will take $t_{1}=33$ minutes for the $0.8 \mathrm{~m}$ web and $t_{2}=27.5$ minutes for the $1.0 \mathrm{~m}$ web. The maximum, temporary capacity that determines the efficiency of conveyors used in the sinking machine is $V_{\text {umax } 1}=$ $129 \mathrm{~m}^{3} / \mathrm{h}$ for the $0.8 \mathrm{~m}$ web and $V_{\text {umax } 1}=157 \mathrm{~m}^{3} / \mathrm{h}$ for the $1.0 \mathrm{~m}$ web. The volume of output from one layer with a depth of $0.3 \mathrm{~m}$ for a shaft diameter of $\phi 9.5 \mathrm{~m}$ is $\mathrm{V}_{\mathrm{w}}=34,7$ $\mathrm{m}^{3}$. Momentary surplus of output in relation to the assumed haulage efficiency in practice will enable the implementation of auxiliary processes. It is anticipated that the location of the complex may be corrected, the cutting head cleaned, etc. It should be noted that in order to obtain the given capacities it is necessary to maintain the specified cutting depth of $\mathrm{H}_{\mathrm{ur}}$, at the same time it is important that the cutting head load can be reduced the most easily by reducing this value. Hence, it is possible to smoothly adapt the head's load to the existing conditions.

Determining the yield obtained from one layer allows to estimate the maximum volume of output and select the means of hauling. In order to be able to determine the progress of shaft sinking or the nominal duration of the investment, it is necessary to take into account the time needed to lower the platform for another web and the time needed to move the entire complex by the set value associated with the stroke of vertical actuators. The analysis of the progress of shaft sinking was carried out for the following assumptions:

- The daily working time of the sinking machine is $T=20 \mathrm{~h}$,

- Time for inspections, revisions and daily maintenance $T_{r}=4 \mathrm{~h}$,

- Processes related to the lining and transport are carried out in parallel,

- To the time of excavating each layer the organizational time was added tow $=15$ $\min$,

- The time of moving the platform by $\mathrm{H}_{\mathrm{ur}}=0.3 \mathrm{~m}$ was assumed as $\mathrm{t}_{\mathrm{w}}=1 \mathrm{~h}$,

- The time of moving the complex by $\mathrm{H}_{\mathrm{k} 1}=1.2 \mathrm{~m}$ and $\mathrm{H}_{\mathrm{k} 2}=2.1 \mathrm{~m} \mathrm{t}_{\mathrm{k}}=2 \mathrm{~h}$,

- Number of working days per year: 260 days (52 weeks $x 5$ days),

- The time needed for failure removal has been taken into account by means of the percentage utilization of the complex. Usage was assumed at the level of $\eta=40 \%$,

- The analysis was carried out for 4 cases:

○ case 1 : web $Z_{1}=0.8 \mathrm{~m}$, stroke $H_{p 1}=0.9 \mathrm{~m}$,

○ case 2: web $Z_{1}=0.8 \mathrm{~m}$, stroke $H_{\mathrm{p} 2}=1.8 \mathrm{~m}$,

○ case 3: web $Z_{2}=1.0 \mathrm{~m}$, stroke $H_{p 1}=0.9 \mathrm{~m}$,

o case 4 : web $Z_{2}=1.0 \mathrm{~m}$, stroke $H_{p 1}=1.8 \mathrm{~m}$.

For the assumptions made and the parameters set previously, a number of values were calculated, which were listed for the given cases in Table 2. The calculation of, among others, the time of single layer execution, cutting time for the progress related to the stroke of actuators, average daily progress, percent utilization of the cutting head and the total time of shaft sinking.

Analyzing the results summarized in Table 2, it can be concluded that the results of the efficiency of exploitation with the present shaft complex are satisfactory for each case. The daily progress fulfills the values assumed by the user. It should be noted that only 5 days of work a week were assumed and a low percentage of use of the complex was assumed, amounting to $\eta=40 \%$. 
Table 2

Analysis of efficiency and time of shaft sinking for all cases

\begin{tabular}{|c|c|c|c|c|}
\hline Parameters & $\begin{array}{l}Z_{1}=0.8 m \\
H_{p 1}=0.9 m\end{array}$ & $\begin{array}{l}Z_{1}=0.8 m \\
H_{p 2}=1.8 m\end{array}$ & $\begin{array}{l}Z_{2}=1.0 m \\
H_{p 1}=0.9 m\end{array}$ & $\begin{array}{l}Z_{2}=1.0 m \\
H_{p 2}=1.8 m\end{array}$ \\
\hline \multicolumn{5}{|c|}{ Analysis of efficiency and time for one layer } \\
\hline Time of one layer cutting $t_{w}$ & $30 \mathrm{~min}$ & $30 \mathrm{~min}$ & $27.5 \mathrm{~min}$ & $27.5 \mathrm{~min}$ \\
\hline Organization time for a layer tow & $15 \mathrm{~min}$ & $15 \mathrm{~min}$ & $15 \min$ & $15 \min$ \\
\hline Time of return tpw & $3 \mathrm{~min}$ & $3 \mathrm{~min}$ & $3 \mathrm{~min}$ & $3 \mathrm{~min}$ \\
\hline Time of the platform lowering $\mathrm{H}_{\mathrm{ur}}$ & $60 \mathrm{~min}$ & $60 \mathrm{~min}$ & $60 \min$ & $60 \mathrm{~min}$ \\
\hline Time to make one layer & $108 \mathrm{~min}$ & $108 \mathrm{~min}$ & $106 \mathrm{~min}$ & $106 \min$ \\
\hline Percentage of the use of the cutting head & $28 \%$ & $28 \%$ & $26 \%$ & $26 \%$ \\
\hline \multicolumn{5}{|c|}{ Analysis of time and efficiency for the stroke of vertical cylinders $\mathrm{H}_{\mathrm{p}}$} \\
\hline Time of lowering the complex by $\mathrm{H}_{\mathrm{k} 1}$ & $120 \mathrm{~min}$ & $120 \mathrm{~min}$ & $120 \mathrm{~min}$ & $120 \mathrm{~min}$ \\
\hline Number of layers made $\left(\mathrm{H}_{\mathrm{k} 1} / \mathrm{H}_{\mathrm{ur}}\right)$ & 4 layers & 7 layers & 4 layers & 7 layers \\
\hline Cutting time to obtain $\mathrm{H}_{\mathrm{k} 1}$ progress & $492 \min$ & $816 \mathrm{~min}$ & $482 \mathrm{~min}$ & $799 \min$ \\
\hline including the head's working time & $120 \mathrm{~min}$ & $210 \mathrm{~min}$ & $110 \mathrm{~min}$ & $192.5 \mathrm{~min}$ \\
\hline Percentage of the use of the cutting head & $24 \%$ & $26 \%$ & $23 \%$ & $24 \%$ \\
\hline Average progress $\mathrm{m} /$ day for $\mathrm{T}=20 \mathrm{~h} /$ day & $2.88 \mathrm{~m}$ & $2.94 \mathrm{~m}$ & $2.88 \mathrm{~m}$ & $3.15 \mathrm{~m}$ \\
\hline \multicolumn{5}{|c|}{ Analysis of time and efficiency for the shaft with a depth of $830 \mathrm{~m}$} \\
\hline Sinking time & 289 days & 283 days & 289 days & 264 days \\
\hline $\begin{array}{l}\text { Number of working hours of the sinking } \\
\text { machine }\end{array}$ & 1.11 year & 1.09 year & 1.11 year & 1.02 year \\
\hline $\begin{array}{c}\text { Number of working hours of the sinking } \\
\text { machine }\end{array}$ & $83000 \mathrm{~h}$ & $83000 \mathrm{~h}$ & $76083 \mathrm{~h}$ & 7608 \\
\hline Shaft sinking time for $\eta=40 \%$ & 2.78 years & 2.72 years & 2.78 years & 2.54 years \\
\hline
\end{tabular}
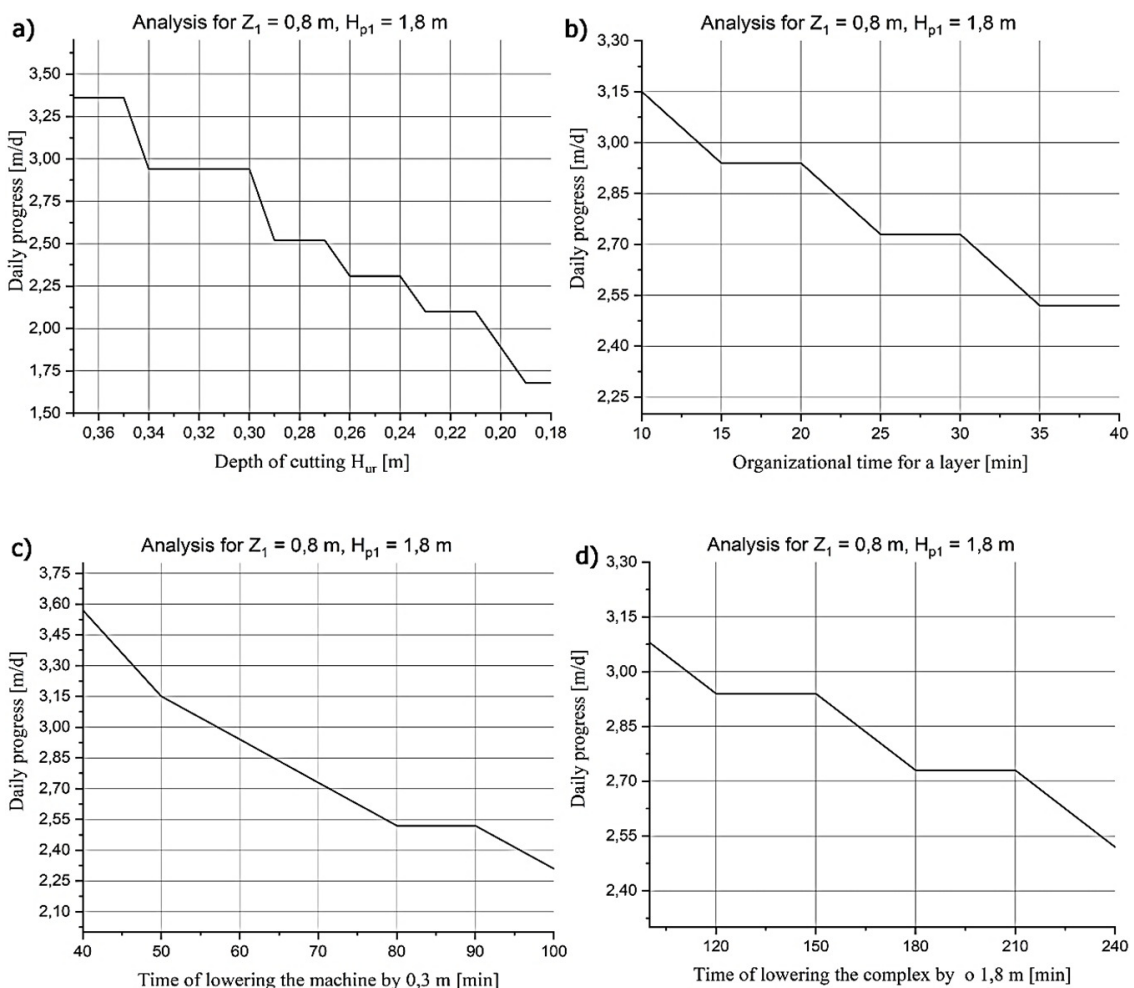

Fig. 4 Daily cutting progress in the function of:

a) depth (thickness) of a single layer, b) time of one layer execution,

c) time of lowering the machine by $0.3 \mathrm{~m}$, d) time of lowering the machine by $1.8 \mathrm{~m}$

The efficiency of shaft sinking is influenced both by the web and the stroke of vertical actuators. However, the results obtained are similar to each other, so that the choice of a particular solution should not be dictated by efficiency, but technical considerations such as availability, ease of assembly. Increasing the web to $1.0 \mathrm{~m}$ 
has a positive effect especially on the working time of the sinking machine. On the other hand, the change in stroke of vertical actuators to $1.8 \mathrm{~m}$ increases the daily progress. In order to achieve the assumed progress, it is important to maintain the assumed depth of cut, feed speed and observe the organizational times associated with the relocation of the platform and the sinking machine. The influence of duration of individual operations and the depth of a single layer (depth of cut) on the progress of daily cutting is shown in Figure 4. A characteristic feature is the discontinuity of the course resulting from the necessity to terminate the processes currently underway before the revision change.

The graphs in Figure 4 show the impact of individual parameters on the daily progress expressed in the number of meters made within 20 hours. Figure 5 shows an example of theoretical analysis of progress as a function of many parameters.

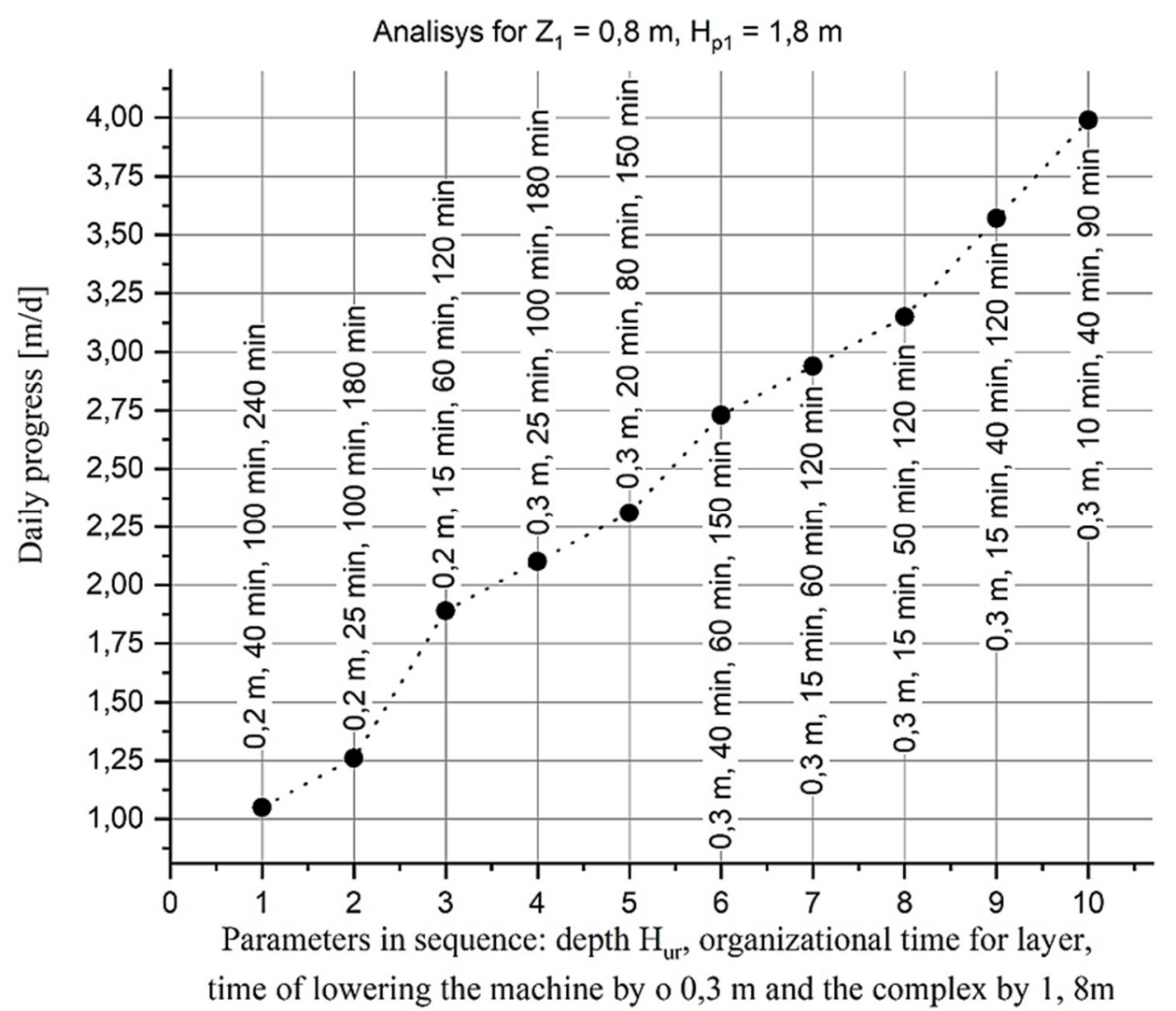

Fig. 5 Multicriteria analysis of the sensitivity of the daily progress of the complex

This analysis presents several selected combinations of parameters whose values are given in the graph. Subsequent changes were done in the depth of cut (thickness of a single layer) from $0.2 \mathrm{~m}$ to $0.3 \mathrm{~m}$; the organizational time added up to the time of executing a single layer from 10 minutes to 40 minutes; time of lowering the machine on vertical actuators by $0.3 \mathrm{~m}$ in the time range from 40 minutes to 100 minutes as well as the time of lowering the whole complex by $1.8 \mathrm{~m}$ in the time range from 90 minutes to 240 minutes. Parameters were changed non-linearly and nonchronologically, and they were selected so as to obtain an increasing trend of daily progress. The analysis is aimed at presenting the sensitivity of cutting efficiency to the change of selected parameters. 


\section{CONCLUSION}

Shaft sinking is a difficult and complicated process. The large variety of mining and geological conditions significantly limits the possibility of developing a universal shaft complex. The introduction of full process mechanization assuming the possibility of carrying out some activities in parallel required the development of a new shaft complex for specific conditions. The presented machine differs from the known complexes and is covered by patent protection under the utility model PL $68320 \mathrm{Y} 1$.

The technical parameters of subsequent devices and organizational parameters related to the processes carried out are affecting the daily progress of the complex. The analysis of the effectiveness of the solution in question as a function of technical and organizational parameters is crucial for the total duration of the investment. The conducted, multi-variant analysis of performance of the shaft sinking showed the possibility of achieving a satisfactory total time of investment implementation. Cutting progress was calculated as a function of the most important parameters, whose value in practice may depend not only on the existing conditions, but also on the experience and involvement of the staff. The analysis takes into account four configurations of the parameters of the complex depending on the cutting head web and the stroke of the vertical actuators. The maximum sinking time for $830 \mathrm{~m}$ deep shaft was determined for less than three years.

\section{REFEENCES}

Allenby, D. and Kilburn, D. (2015). Overview of underpinning and caisson shaft-sinking techniques. Proceedings of the institution of civil engineers-geotechnical engineering, 2, pp. 3-15.

Biały, W. (2016). Determination of workloads in cutting head of longwall tumble heading machine. Management Systems in Production Engineering, 1(21), pp. 45-54.

Bołoz, $Ł$. and Krauze, K. (2018). Ability to mill rocks in open-pit mining. In: 18th International Multidisciplinary Scientific Geoconference, Exploration and Mining, SGEM2018, Albena, Bulgaria, Voulme 2, pp. 41-48.

Casteel, K. (2009). Shaft Sinking Technology: The Long and the Short of It. E\&MJ-Engineering and Mining Journal, 4, pp. 36-38.

Gospodarczyk, P, Kotwica, K., Mendyka, P. and Stopka, G. (2016). Innovative roadheader mining head with assymetrical disc tools, Exploration and mining, mineral processing. International Multidisciplinary Scientific GeoConference SGEM, Sofia, 2, pp. 489-496.

Gospodarczyk, P., Kotwica, K. and Stopka, G. (2013). A new generation mining head with disc tool of complex trajectory, Archives of Mining Sciences, 58(4), pp. 985-1006.

Kotwica, K. (2018). Atypical and innovative tool, holder and mining head designed for roadheaders used to tunnel and gallery drilling in hard rock. Tunnelling and Underground Space Technology, 82, pp. 493-503.

Krauze, K., Bołoz, $Ł$. and Wydro T. (2018). Mechanised shaft sinking system, Archives of Mining Sciences, 63(4), pp. 891-902.

Schmah, P. (2007). Vertical shaft machines. State of the art and vision. Acta Montanistica Slovaca, 12(1), pp. 208-216.

Sitko, J., Mikus, R. and Bożek, P. (2018). Analysis of device failure in the mechanical production plant. MAPE 2018. XV International Conference Multidisciplinary Aspects of Production Engineering, 05-08 September 2018, Zawiercie, Poland. Conference proceedings, 1(1), pp. 93-99.

Tokarczyk, J. (2015). Method for virtual prototyping of cabins of mining machines operators. Archives of Mining Sciences, 60(1), pp. 329-340. 
Abstract. In underground mines, where the deposit is located at considerable depths, mining shafts are key excavations. The project of making the deposit available requires selection of appropriate shaft sinking technology adapted to geological and hydrological conditions and natural hazards. Shafts can be made using the classic drilling and blasting technique or mechanical cutting of the shaft face. Mechanical cutting requires the use of a mining machine, which together with machines for loading and hauling the output and protecting the side walls is a shaft complex. Drilling using mechanized shaft complexes allows for high efficiency and work safety. To improve the efficiency of drilling, it is particularly important to implement many processes in parallel. The article presents an analysis of the progress of shaft sinking with a mechanized complex as a function of technical and organizational parameters. The analysis concerned a new generation cutting shaft complex, developed for the needs of shaft sinking for one of the Polish hard coal mines. The calculations were carried out for a shaft with a maximum diameter of $9.5 \mathrm{~m}$ and a total depth of $830 \mathrm{~m}$. The article briefly presents a new solution for the shaft complex. There are presented results of calculations of daily drilling progress and total time of shaft sinking for the developed working technology of this complex. The efficiency of the complex depends on many factors related to technical parameters of individual machines and devices forming the complex and organizational parameters, hence a multi-variant analysis was carried out.

Keywords: shaft complex, performance analysis, shaft sinking, daily progress, mechanical cutting 